\title{
Forms of governance and the size of rent-seeking
}

\author{
Luis C. Corchón
}

Received: 28 July 2004 / Accepted: 7 February 2007

(C) Springer-Verlag 2007

\begin{abstract}
In this paper we present a model where agents can choose between productive and rent-seeking activities. We consider two governance institutions: autocracy and parliament rule. Under autocracy rent-seeking reflects the taste of the autocrat for such activities. Under parliament rule rent-seeking depends on parliament voting. We show that under parliament rule the size of rentseeking may be larger than under autocracy. This cast doubts on the idea that "rigth" institutions necessarily promote good economic performance. We also show that rent-seekers may be interested in overthrowing autocracy.
\end{abstract}

\section{Introduction}

This paper studies how governance affects the relative size of productive and rent-seeking activities. We consider two forms of governance, autocracy or single ownership, where governance is made by a single agent and corporate governance or parliamentary rule, where governance is made by majority voting. Here there are three examples of the kind of situations to which our model can be applied.

1: Kingdoms. In Europe from the seventeenth century on, some countries were ruled by the parliament (e.g. Netherlands and Great Britain) while others (e.g. Spain and Portugal) were absolute monarchies.

I am grateful to an anonymous referee, G. Aldashev, S. Battilossi, C. Beviá, J. Carmona, P. Fraile, C. E. García, S. Houpt, C. Litan, B. Moreno, P. Revilla, G. Zudenkova, the participants in seminars at universities Carlos III (Economic History and Economics) and Autònoma de Barcelona for helpful comments and to CICYT under grant BEC2002-02194 and to BBVA for financial support.

L. C. Corchón $(\bowtie)$

Department of Economics. Universidad Carlos III, c/ Madrid 126, Getafe, 28903 Madrid, Spain

e-mail: lcorchon@eco.uc3m.es 
2: Location. In some countries there is a stark contrast between industrial regions/cities (e.g. Milan, Barcelona) and the capital of the nation (Rome, Madrid). The folklore attaches to the former the role of industrious people and to the latter the role of rent-seekers.

3: Governance of a firm. Here we have two regimes: Single ownership and corporate firms in which the owner is reduced to the role of a powerless supplier of capital (Berle and Means 1932). In the latter, decisions are taken by majority voting by managers sitting on a Board of Directors.

Under autocracy, the single owner collects taxes and provides the prize sought by rent-seekers (i.e. land, servants, nobiliary titles, etc.). Active agents might either be rent-seekers or producers, also called entrepreneurs. Free entry in rent-seeking and productive activities determines the number of active agents in each activity. In the case of a kingdom this means that the noble may be either courtier or entrepreneur. In the case of a firm this means that managers can either direct a division of the firm or devote time and effort to unproductive activities at the top. Given an allocation of active agents, the autocrat chooses a tax rate that maximizes his income. Taxes finance the consumption of the autocrat and the prize. Given a tax rate, entrepreneurs choose quantities to maximize profits and rent-seekers choose efforts to maximize payoffs (in an attempt to obtain the prize). An equilibrium is a situation where all agents maximize. We prove that such an equilibrium exists, is unique and stable (Propositions 1 and 2). We find that, depending on the form of demand functions, exogenous technological progress may increase or decrease the relative size of rent-seeking (Remark 1). ${ }^{1}$

Next, we consider Parliament Rule where the decision about the tax rate is taken by majority voting in a parliament composed of all active agents. Recall that early parliaments were mainly populated by owners and noblemen. In the case of a firm, the parliament is the board of directors (BOD). The BOD is composed of agents that either represent the production side, whose salaries are linked to profits of the division they command, or rent-seekers whose incomes depend on salaries and perks obtained as BOD members. Under parliament rule, we assume that a prize might be awarded, provided the necessary taxes are voted by the parliament. We find that there are two equilibria. In one of those, rent-seeking activities disappear because the parliament is composed entirely of entrepreneurs and their most preferred tax rate is zero (Remark 2). This equilibrium always exists. But there might be another equilibrium in which the parliament is dominated by rent-seekers. In this case, they vote for a tax rate that maximizes total revenue. This tax coincides with the tax set by the autocrat. We provide conditions under which the latter equilibrium exists (Propositions 3 and 4). We find that some of these conditions are plausible. In this equilibrium, the number of rent-seekers is larger than under autocracy because taxes are now entirely devoted to producing the prize. Consequently, in this equilibrium,

1 Thus, the rent-seeking sector may decrease for reasons other than governance. We notice that productivity increased steadily in Europe in the 150 years that preceded the industrial revolution, North (1981, p. 166). 
the number of entrepreneurs falls and the price of output rises with respect to those under autocracy (Proposition 5).

Finally, we deal with equilibrium selection, i.e. with the question of which particular equilibrium actually occurs. We assume that when the autocrat is deposed, the existing active agents vote in a provisional parliament about taxes. We see that under not unreasonable conditions they select the tax that maximizes income (Proposition 6). This and the previous results point out that the existence of a parliament is not a sufficient condition for promoting the productive sector.

We compare our results with others obtained in the literature.

1: Parliaments and rent-seeking: "Absolutist states... such as early modern Spain, created economic conditions that retarded long-run economic growth" (North and Weingast 1989, p. 808). This was because under the old regime rent-seeking was rampant (Ekelund and Tollinson 1981). Conversely, strong economic performance, like in England and the Netherlands, was the effect of the rule of parliament with little rent-seeking (North 1990). However, according to Buchanan and Tullock (1962) and Olson (1982), parliaments can foster rent-seeking activities. Our model gives some merit to both views since Parliaments might be free from rent-seekers but existence of a parliament is neither a necessary, nor a sufficient condition for rent-seeking to vanish.

2: Institutions vs. policies: According to the "New Institutional Economics" good economic performance is the effect of institutions that constraint government (North 1981, 1990, Acemoglu et al. 2001, Easterly and Levine 2003 and Rodrik et al. 2004). This view has been criticized by Glaeser et al. (2004). They stress the role of human capital and good policies for good economic performance. Again our model gives some merit to both views but stress that there is not a single-valued mapping between institutions and policies.

3: Rent-seeking and economic performance: Murphy et al. (1991) and Acemoglu (1995) presented models of organizations where productive and rent-seeking activities coexist. Mohtadi and Roe (2003) study how the size of productive and rent-seeking activities affect growth focussing on the flow of information and access to the government. Gradstein (2004) studies the relationship between growth and the enforcement of property rights whose equilibrium level is determined by utility maximization of the representative agent. All these papers are silent on issues of governance which is the main focus of our paper. ${ }^{2}$

The paper is organized as follows. Section 2 explains the model. Section 3 gathers our results. The paper ends with a section of conclusions which comments on our assumptions and offers some suggestions for future research.

\footnotetext{
2 In our model machanisms of external controil of the organization are missing (i.e. corrupt parliaments can be controlled by voters and corrupt BOD can be controlled by competition), This is done to highlight the similitudes between parliaments and BOD.
} 


\section{The model}

The organization produces two kinds of goods: The good sought by rent-seekers, which we will call the prize (a position in a committee/a duchy) and a differentiated good. There is a sole input (labor/capital) which is the numeraire.

The single owner (autocrat) collects revenues by a tax on output. ${ }^{3}$ Let $t$ be the tax rate. The autocrat transforms part of taxes in the prize.

There are $N$ active agents who either organize the production inside the organization, call them entrepreneurs, or are rent-seekers. Suppose that there are $m$ entrepreneurs (later on we will explain how the equilibrium value of $m$ is determined). Each entrepreneur produces a differentiated good and faces an inverse demand function of the following form,

$p_{i}=a-b\left(x_{i}+\theta \sum_{j \neq i} x_{j}\right)^{\alpha}-t, \quad$ with $a \geq 0, \alpha>-1, b \alpha>0$, and $0<\theta \leq 1$,

where $p_{i}$ and $x_{i}$ are the price and output of good $i . \theta$ measures the degree of product differentiation. $\alpha$ is a measure of the curvature of demand function (inverse demand is concave iff $\alpha \geq 1$ ). $b$ is an inverse measure of the size of the market since the maximum consumption of the good $i$ obtains when $x_{i}=((a-t) / b)^{\frac{1}{\alpha}}$. The slope of the demand function is determined by the sign of $-\alpha b$ and thus, it is negative. Assuming, by simplicity, $\theta=1$ and letting $x \equiv \sum x_{i}$, if $\alpha=1$ and $b>0$, demand functions are linear in $x$ and if $a=0, b<0, \alpha<0$, demand functions are isoelastic in $x$ with elasticity $-1 / \alpha$. Demand functions might be exogenously determined or derived from the utility maximization of a representative consumer who supplies the input, pays taxes and consumes the goods produced. ${ }^{4}$

Each entrepreneur has access to assets (i.e. technology) that allow him to convert one unit of input in $1 / \mathrm{g}$ units of product. Thus, $1 / \mathrm{g}$ is the productivity of the input in the productive sector. We will assume that $(a-g) / b>0$. In the linear case it means that the marginal cost is below the price that makes demand zero. In the isoelastic case, it means that the marginal cost is positive.

Profits for $i$, denoted by $B_{i}$, are $B_{i} \equiv\left(a-b\left(x_{i}+\theta \sum_{j \neq i} x_{j}\right)^{\alpha}-t-g\right) x_{i}{ }^{5}$ Firm $i$ maximizes $B_{i}+\gamma \sum_{j \neq i} B_{j}, 0 \leq \gamma \leq 1$. If $\gamma=0$ the entrepreneurs act independently. If $\gamma=1$ aggregate profit equals individual profit and the

\footnotetext{
3 In our model only the owner can set taxes. For a model where active agents can also set taxes see Rosenthal (Bates et al. 1998).

4 If, for simplicity, we assume that the product is homogeneous, preferences of the consumer are representable by the following utility function where $l$ is consumption of the input (leisure):
}

$$
u=a x-\frac{b x^{\alpha+1}}{\alpha+1}-l
$$

5 In the case of a kingdom profits are spent in the labor market. 
production sector is a team. Thus, $\gamma$ reflects the degree of collusion among producers. We assume that firms are quantity-setters. First order condition (FOC) of maximization are

$$
\begin{aligned}
& a-t-g-b\left(x_{i}+\theta \sum_{j \neq i} x_{j}\right)^{\alpha}-\alpha b\left(x_{i}+\theta \sum_{j \neq i} x_{j}\right)^{\alpha-1} x_{i} \\
& -\gamma \alpha b \theta \sum_{j \neq i} x_{j}\left(x_{j}+\theta \sum_{r \neq j} x_{r}\right)^{\alpha-1}=0
\end{aligned}
$$

It can be shown that second order conditions hold and the system of FOC has only symmetric solutions. At the unique equilibrium, output and prices are

$$
\begin{gathered}
x_{i}=\left(\frac{(a-g-t)(1+\theta(m-1))^{1-\alpha}}{b(1+\theta(m-1)+\alpha(1+\gamma \theta(m-1))}\right)^{\frac{1}{\alpha}} . \\
p_{i}=\frac{\alpha(a-t-g)(1+\gamma \theta(m-1))}{1+\theta(m-1)+\alpha(1+\gamma \theta(m-1))}+g .
\end{gathered}
$$

Since equilibrium is symmetric, let us denote the market price by $p$.

Let $n(=N-m)$ be the number of rent-seekers. Let $V$ the value that they attribute to the prize. Rent-seekers must exert effort in order to attract the attention of the autocrat. Let $G_{i}$ be the effort (time spent nearby the autocrat, cost of banquets, etc.) made by the rent seeker $i$. The probability that $i$ gets the prize is

$$
\sigma_{i}=\frac{G_{i}^{\epsilon}}{\sum_{j=1}^{n} G_{j}^{\epsilon}}, \quad \epsilon \in[0,1] .
$$

$\epsilon$ measures the responsiveness of $\sigma_{i}$ to efforts (see Pérez-Castrillo and Verdier 1992). If $\epsilon=0, \sigma_{i}=1 / n$. If $\epsilon=1$ we have the function proposed by Tullock (1980). $\sigma_{i}$ can also be interpreted as the fraction of the prize obtained by $i$.

We assume that the cost of effort, denoted by $C_{i}$ is linear, $C_{i}=c G_{i}, c>0$. Thus, payoffs for $i$ are

$$
\Pi_{i}=\frac{G_{i}^{\epsilon}}{\sum_{j=1}^{n} G_{j}^{\epsilon}} V-c G_{i} .
$$

Given $V$ and $n$ each rent-seeker chooses effort in order to maximize payoffs taken as given the effort of other rent-seekers. FOC of payoff maximization are

$$
\frac{\epsilon G_{i}^{\epsilon-1} \sum_{j=1}^{n} G_{j}^{\epsilon}-\epsilon G_{i}^{\epsilon-1} G_{i}^{\epsilon}}{\left(\sum_{j=1}^{n} G_{j}^{\epsilon}\right)^{2}} V=c, \quad i=1,2, \ldots, n .
$$


It is easy to see that the second order condition holds and that the system above only includes symmetrical solutions. ${ }^{6}$ This yields,

$$
\begin{gathered}
G_{i}=\frac{\epsilon(n-1) V}{n^{2} c} . \\
\Pi_{i}=\frac{V(n-\epsilon(n-1))}{n^{2}} .
\end{gathered}
$$

The utility function of the autocrat is $U=\left(\sum_{i=1}^{n} G_{i}\right)^{\beta} C^{1-\beta}, 0<\beta<1$ where $C$ is his consumption of the numeraire. The prize is produced by the autocrat under constant returns to scale. Let $e$ be the average productivity of the input in the production of the prize. An interpretation is that the prize consists of the value of the input plus the prestige given by the status achieved with the prize. In this case, $e>1$ reflects the value added by the status. ${ }^{7}$ Also $e$ reflects the degree of law enforcement of the laws that provide a legal cover for the prize owner.

Taxes can be spent either in $C$ or in the production of the prize. Hence $C+V / e=T$. Taxes are set by the autocrat. The maximization of his utility can be made in two steps. First the autocrat maximizes $T$ and, later on he decides how to divide his income between $C$ and $V$.

We assume that when the autocrat maximizes $T$ he assumes that the number of rent seekers is given. This is because the decision to enter one of the two activities is a long run decision requiring a particular kind of education in the early youth and so is not likely to be influenced by changes in the tax rate. In the kingdom model, this may be interpreted as saying that agents cannot change occupation, only the descendents - perhaps involving an adequate marriage. Under this interpretation agents are families. In the location model, the interpretation of this assumption is that entrepreneurs and rent-seekers live in different parts of the country and relocation is costly. In the model of a firm, the interpretation is that to change profession involves a high transaction cost. Given that $T=t \sum_{i=1}^{m} x_{i}$,

$$
T=t\left(\frac{(a-g-t)(1+\theta(m-1))^{1-\alpha}}{b(1+\theta(m-1)+\alpha(1+\gamma \theta(m-1))}\right)^{\frac{1}{\alpha}} m .
$$

The above is the Laffer curve of our economy. Maximization of $T$ amounts to choosing $t$ to maximize $t(a-g-t)^{\frac{1}{\alpha}}$ subject to $0 \leq t \leq a-g$ (the second inequality says that output is non-negative, see (2.1)). Given that $T$ is continuous in $t$ and $t$ belongs to a compact set, the maximum exists. The maximum

6 Collusion does not alter the results significatively: If each rent-seeker maximizes $\Pi_{i}+\eta \sum_{j \neq i} \Pi_{j}$, $0 \leq \eta \leq 1$, the equations in the main text hold with $\epsilon$ substituted by $\epsilon(1-\eta)$.

${ }^{7}$ For the sale of titles in the seventeenth century see North and Weingast (1989), p. 811. 
cannot be located at the extremes, where $T=0$, so it must be located at FOC,

$$
(a-g-t)^{\frac{1}{\alpha}}\left(1-\frac{t}{\alpha(a-g-t)}\right)=0 .
$$

There is only one value of $t$ that solves the previous equation and yields positive revenue, namely

$$
t^{*}=\frac{\alpha(a-g)}{1+\alpha} .
$$

Notice that $t^{*}>0$ since $\alpha b>0$ and $\frac{a-g}{b}>0$ and $t^{*}<a-g$ because $\alpha /(1+\alpha)<1$. Denote by $\bar{T}$ the taxes levied. Now let us study the distribution of $\bar{T}$ between consumption and the prize. We assume that the autocrat correctly anticipates the efforts of rent-seekers as a function of $V$. Hence $U=\left(\frac{\epsilon(n-1) V}{n c}\right)^{\beta}(C)^{1-\beta}$. The utility function can be re-written as $U=V^{\beta} C^{1-\beta}$. The maximization of utility given $\bar{T}$ yields $C=\bar{T}(1-\beta)$ and $V=e \beta \bar{T}$.

Finally, we assume that active agents can freely enter into rent-seeking or production activities. Assuming for simplicity that $n$ and $m$ are real numbers, free entry implies that

$$
B_{i}=\Pi_{i}
$$

The game is played in three stages. In the first, active agents decide if they produce or become rent-seekers. In the second, the autocrat maximizes revenues and builds the prize. In the last stage, effort of rent-seekers and production takes place. ${ }^{8}$ The equilibrium is a subgame perfect equilibrium where, in each stage, each agent assumes that other agents will act optimally in the rest of the game. Formally,

Definition 1 An autocratic organization is in equilibrium if:

1. No active agent wants to switch occupation, i.e., (2.4) holds for $n+m=N$.

2. Given $n$ and $m$, the autocrat maximizes tax revenues, i.e. (2.3) holds.

3. Given $n$ and $V$, rent-seekers maximize payoffs, i.e. (2.2) holds.

4. Given $t$ and $m$, the product market is in equilibrium, i.e. (2.1) holds.

Consider now corporate governance. Here there is a parliament (board of directors) that is composed of all active agents that decide the tax rate by majority voting. The autocrat is now a constitutional king (a CEO). He receives an stipend that for simplicity we assume is zero. The prize is produced and awarded as before. Rent-seeking is either organized by the autocrat or by rent-seekers themselves. The new equilibrium is defined as follows:

Definition 2 A corporate governance organization is in equilibrium if:

1. No active agent wants to switch occupation, i.e., (2.4) holds for $n+m=N$.

2. Given $n$ and $m$, the parliament decides about $t$ by majority voting.

\footnotetext{
8 The order of stages is identical to that in many models of Industrial Organization: first location, followed by the decicion about the tax and, finally, competition.
} 
3. Given $n$ and $V$, if there are rent-seekers, they maximize payoffs, i.e. (2.2) holds.

4. Given $t$ and $m$, the product market is in equilibrium, i.e. (2.1) holds.

This equilibrium is identical to that of autocracy except that taxes are voted by the parliament and that there is no consumption of the autocrat.

\section{Results}

Our first result is the following:

Proposition 1 There is a unique equilibrium for autocracy.

Proof Since $B_{i}=(p-g) x_{i}$, Eqs. (2.2') and (2.4) imply that

$$
(p-g) x_{i}=\frac{e \beta t x(n-\epsilon(n-1))}{n^{2}} \quad \text { or } \quad n^{2}(p-g)=e \beta t(n-\epsilon(n-1)) m .
$$

Since $t^{*}=\frac{\alpha(a-g)}{1+\alpha}$, from $\left(2.1^{\prime}\right)$ we obtain that

$$
\frac{t^{*}}{p-g}=\frac{1+\theta(m-1)}{1+\gamma \theta(m-1)}+\alpha
$$

Simplifying and taking into account that $m=N-n$,

$$
\frac{n^{2}}{e \beta(n(1-\epsilon)+\epsilon)}-\frac{(N-n)(1+\theta(N-n-1))}{1+\gamma \theta(N-n-1)}-\alpha(N-n)=0 .
$$

The left hand side of (3.1) is positive for $n=N$ and negative for $n=0$. Hence, there is a value of $n$ such that (3.1) holds. Such a value is unique since the left hand side of (3.1) is strictly increasing in $n$. Given this value of $n$, the equilibrium values of $x_{i}$ and $G_{j}$ are determined by Eqs. (2.1) and (2.2).

This equilibrium can be regarded as a fixed point of a dynamic process in which the rate of change in the number of entrepreneurs is an increasing function of the difference between $B_{i}$ and $\Pi_{i}$. Let

$$
\frac{\mathrm{d} m}{\mathrm{~d} t}=h\left(B_{i}-\Pi_{i}\right)
$$

where $h($ ) is sign-preserving. Now, we have the following:

Proposition 2 The equilibrium of the autocracy is globally stable, i.e. starting from any $m$, the system tends to the value of $m$ in (3.1).

Proof In the proof of Proposition 1 it was shown that $B_{i}-\Pi_{i}$ was increasing in $n$, and so it is decreasing on $m$. Since $h()$ is sign preserving it follows that $\frac{\mathrm{d} m}{\mathrm{~d} t}$ is a decreasing function of $m$ and this proves the result. 
Once we know that equilibrium is unique and stable we can embark upon the job of analyzing the determinants of the relative size between rent-seeking and productive activities. A measure of this size is the ratio between $V$ and aggregate production denoted by $x \equiv \sum_{i=1}^{m} x_{i}$. This ratio will be denoted by $u$.

$$
u \equiv \frac{V}{x}=\frac{e \beta t^{*} x}{x}=e \beta t^{*}=e \beta \frac{\alpha(a-g)}{1+\alpha}=\frac{e \beta \alpha b}{1+\alpha} \frac{(a-g)}{b} .
$$

Notice that $u$ does not depend on $\epsilon, \gamma, \theta, b, N$ and $c{ }^{9}$ The effects on $u$ of $e$ and $\beta$ are what we expect: For instance a decrease in $e$, reflecting a weaker enforcement of laws that provide a legal cover to rent-seeking, decreases the relative size of it. However the effects of $\alpha$ and $(a-g)$ on $u$ are not that intuitive:

$$
\begin{aligned}
\frac{\mathrm{d} u}{\mathrm{~d} \alpha} & =\frac{\alpha b e \beta}{(1+\alpha)^{2}} \frac{a-g}{\alpha b}>0 \Leftrightarrow \alpha>0 \Leftrightarrow b>0 . \\
\frac{\mathrm{d} u}{\mathrm{~d}(a-g)} & =\frac{e \beta \alpha}{1+\alpha}>0 \Leftrightarrow \alpha>0 \Leftrightarrow b>0 .
\end{aligned}
$$

The effect of $a-g$ on $u$ depends on the impact of $a-g$ on $t^{*}$ since $u=e \beta t^{*}$. Under isoelastic demand $(\alpha<0)$ an increase of $a-g$ reduces $u$ because demand is more elastic and this lowers the revenue maximizing tax. Under linear demand $(\alpha=1)$ an increase in $a-g$ makes demand less elastic and this increases the revenue maximizing tax. The explanation of the effect of $\alpha$ on $u$ follows the previous lines. The bottom line is that technical progress might reduce or increase rent-seeking. The latter effect is similar to what is called the "Dutch disease" in which an increase in endowments lowers income because it increases rent-seeking (Baland and Francoise 2000; Torvik 2002). Summing up all these findings,

Remark 1 In the equilibrium of the autocracy u depends positively on $e$ and $\beta$, is independent of $\epsilon, \gamma, \theta, b, c$ and $N$ and

$$
\operatorname{sign} \frac{\mathrm{d} u}{\mathrm{~d} \alpha}=\operatorname{sign} \frac{\mathrm{d} u}{\mathrm{~d}(a-g)}=\operatorname{sign} \alpha=\operatorname{sign} b
$$

Let us now turn our attention to corporate governance. Under this regime active agents vote the tax rate. Rent-seekers have single peaked preferences with a maximum at $t=t^{*}$. Entrepreneurs have also single-peaked preferences with the maximum at $t=0$. Hence the largest group will impose its most preferred policy.

Remark 2 If $N>2, m=N$ and $t=0$ is an equilibrium of corporate governance.

\footnotetext{
9 Notice that the determinants of $u$ and $n$ are different. We see from (3.1) that $n$ depends positively on $e, \beta, \alpha, \theta$ and $N$, negatively on $\gamma$ and $\epsilon$ and is independent of $a, b, c$ and $g$.
} 
The proof is obvious: if only entrepreneurs exists, the parliament votes a tax rate of zero and no entrepreneur would like to switch to rent-seeking because he would not affect the decision on the tax rate and the prize does not exist.

Let us now study the possibility that rent-seeking exists under parliamentary rule. If it does, rent-seekers must be a majority in the parliament in order to impose a positive tax. And if they are such a majority, $t^{*}$ will result. In this case, the equilibrium number of rent-seekers is identical to that under autocracy with $\beta=1$. This number is determined by (3.1). A general solution to this equation is too involved, so we will consider two extreme cases: no collusion $(\gamma=0)$ and full collusion $(\gamma=1)$. The first case is appropriate for the example of a kingdom or for a divisionalized firm.

Proposition 3 Suppose $\gamma=0$. Under the following conditions there is an equilibrium in which rent-seekers dominate the parliament

a) $2 e(\alpha-\theta+1)>N(1-\theta e)$

b) $e \theta=1$ and $1+\alpha>\theta$.

Proof For the time being take $\epsilon=1$. Write (3.1) with $\beta=1$, and $\gamma=0$ as $n^{2}(1-\theta e)+e(2 N \theta+1-\theta+\alpha) n-\left(\theta N^{2}+N-\theta N+\alpha N\right) e=0$. If $e \theta \neq 1$,

$$
\begin{aligned}
& n= \\
& \frac{-e(2 N \theta+1-\theta+\alpha)+\sqrt{e^{2}(2 N \theta+1-\theta+\alpha)^{2}+4(1-\theta e)\left(\theta N^{2}+N-\theta N+\alpha N\right) e}}{2(1-e \theta)}
\end{aligned}
$$

Tedious algebra shows that $2 n>N$ iff $2 e(\alpha-\theta+1)>N(1-\theta e)$. This is Part a). If $e \theta=1(3.1)$ reads $(2 N \theta+1-\theta+\alpha) n=\theta N^{2}+N-\theta N+\alpha N$. In this case, $2 n>N$ iff $1+\alpha>\theta$.

Finally, let $\epsilon<1$. As noticed in Footnote 9, $n$ is decreasing on $\epsilon$. Thus, if $\epsilon<1$ the number of rent-seekers increases in relationship with those in the case $\epsilon=1$ and the previous result holds a fortiori.

Proposition 3 states two sufficient conditions for the parliament to be dominated by rent-seekers. ${ }^{10}$ The most interesting case is a) that if the product is homogeneous simplifies to $e>1$ and $N>-2 e \alpha /(e-1)$. This holds if the marginal productivity of the input in the production of the prize is larger than one-i.e. if the prize has some status associated to it - and if $\alpha<0, N$ is large. If $\alpha>0$, the first condition suffices. These conditions look reasonable.

Our next proposition studies the case of $\gamma=1$. This scenario is appropriate for a non-divisionalized firm. To simplify calculations we also assume $\theta=1$.

10 These conditions are only necessary when $\epsilon=1$. For instance, if $\epsilon=0$, it is easily calculated from (3.1) that when $N$ is large the parliament is almost exclusively populated by rent-seekers. 
Proposition 4 If $\gamma=1$ necessary and sufficient conditions for the existence of an equilibrium in which the parliament is dominated by rent-seekers are:

a) $e(1+\alpha)(1-\epsilon) \geq 1$ and $\epsilon>0$.

b) $e(1+\alpha)(1-\epsilon)<1$ and $N<\frac{2 e \epsilon(1+\alpha)}{1-e(1+\alpha)(1-\epsilon)}$.

Proof Write (3.1) with $\beta=\gamma=1$ as $n^{2}=(1+\alpha)(N-n) e(n(1-\epsilon)+\epsilon)$, or $(1+(1+\alpha) e(1-\epsilon)) n^{2}-e(1+\alpha)(N(1-\epsilon)-\epsilon) n=e N(1+\alpha) \epsilon$. Solving for $n$

$n=\frac{e(1+\alpha)(N(1-\epsilon)-\epsilon) \pm \sqrt{(e(1+\alpha)(N(1-\epsilon)-\epsilon))^{2}+4(1+(1+\alpha) e(1-\epsilon)) e N(1+\alpha) \epsilon}}{2(1+(1+\alpha) e(1-\epsilon))}$.

Tedious algebra shows that $n>N / 2$ iff $N(1-e(1+\alpha)(1-\epsilon))<2 e \epsilon(1+\alpha)$.

Case a) above holds when $e$ or $\alpha$ are large and $\epsilon$ small. Case b) is identical to

$$
\frac{1}{1-\epsilon}>e(1+\alpha)>\frac{N}{2 e+N(1-\epsilon)}
$$

which looks like a rather special case.

Propositions 3 and 4 are the main results of the paper. They show conditions under which rent-seekers dominate the parliament. It is clear that if the productivity in the production of the prize, $e$, is large enough these conditions are satisfied. But if $e$ is not very large, the case $\gamma=0$ requires considerably weaker conditions than the case $\gamma=1$. This is because competition among divisions lowers the profit from productive activities and makes rent-seeking more attractive. From this it follows that divisionalized organizations have more chances to be captured by rent-seekers than non divisionalized ones.

The relative size of rent-seeking activities under a parliament dominated by rent-seekers is determined by Eq. (3.2) with $\beta=1$. Therefore, Remark 1 applies to this case. We now study other properties of this kind of equilibrium.

Proposition 5 When the parliament is dominated by rent-seekers the number of rent-seekers is larger and the price of output greater than under autocracy.

Proof From Eq. (3.1) is clear that $n$ is increasing in $\beta$. Since the only difference between autocracy and corporate governance when the parliament is dominated by rent-seekers is that in the latter $\beta=1$, the result about $n$ follows. Lastly, it is easy to see in $\left(2.1^{\prime}\right)$ that $p$ is decreasing in $m$.

The logic behind Proposition 5 is that if a parliament is dominated by rent-seekers, all taxes are spent in building the prize and this attracts more rent-seekers. This implies a decline in productive activities and hence the price of output increases. It may be argued that this result is an artifact of our assumption that under corporate governance all taxes are spent on the prize. However, this assumption can be interpreted more broadly. For instance, if a king is 
deposed and his property sold in auction, there is an extra incentive to be a rent-seeker. ${ }^{11}$ Two implications of this proposition are worth noting:

1) The welfare of workers under a parliament dominated by rent-seekers is smaller than what they enjoyed under absolute monarchy. ${ }^{12}$

2) If there is a majority of rent-seekers, they might be in favor of deposing the absolute monarch who, from their point of view is nothing but an intermediary. 13

We end this section by studying the problem of which equilibrium is more likely to occur, i.e. the equilibrium selection. We assume that when the autocrat is deposed, a provisional parliament forms. This parliament is composed of the entrepreneurs and rent-seekers under the previous regime. Our result is:

Proposition 6 Under the following conditions the provisional parliament is dominated by rent-seekers

a) If $\gamma=0,2 \beta e(\alpha-\theta+1)>N(1-\theta \beta e)$ or $\beta e \theta=1$ and $1+\alpha>\theta$.

b) If $\gamma=1, e \beta(1+\alpha)(1-\epsilon) \geq 1$ and $\epsilon>0$ or $e \beta(1+\alpha)(1-\epsilon)<1$ and $N(1-e \beta(1+\alpha)(1-\epsilon))<2 e \epsilon(1+\alpha)$.

Proof Notice that $e$ and $\beta$ enter as a product in (3.1). Thus, all the reasonings made in Propositions 3 and 4 can be made with $e$ substituted by $\beta e$.

Again, the most plausible condition arises when $\gamma=0$. If the product is homogeneous and $\beta e>1$, a large $N$ (larger than $2 \beta e \alpha /(\beta e-1)$ ) suffices for this condition to hold. Notice that autocrats with $\beta^{\prime} s$ close to zero are likely to yield parliaments dominated by entrepreneurs. This provides some background to the observation that "poor countries get out from poverty through good policies, often pursued by dictators, and subsequently improve their political institutions" (Glaeser et al. 2004, p. 271).

\section{Conclusion}

The main conclusion of this paper is that the existence of a parliament is neither necessary nor sufficient condition for the decline of rent-seeking; it is possible that technical progress makes the finance of rent-seeking activities increasingly difficult (Remark 1), and the parliament might be dominated by rent-seekers (Propositions 3 and 4). Also our analysis points out that when an eventual parliament would be dominated by rent-seekers, rent-seekers are interested in

\footnotetext{
11 This may explain the large amount of rent-seeking in 19th century Spain. At this time the property of the church and the commons were auctioned and this provided an extra incentive for rent-seeking. See Fraile-Balbín (1991) for the role of rent-seeking in the slow development of Spain.

12 This reminds the Marxist belief that workers had little to gain with a burgeoise regime.

13 This analysis, mutatis mutandis, can be applied to the process of decolonization and suggests a reason for local rent-seekers to fight against colonial powers.
} 
overturning the absolute king (Proposition 6). ${ }^{14}$ Finally, the size of rent-seeking might be larger under parliament rule than under autocracy.

From the historical point of view our conclusions cast doubts on the belief that the parliament "... control over the exercise of arbitrary and confiscatory power by the Crown", North and Weingast (1989), p. 804. As these authors recognize, "the triumph of Parliament raises the issue of why it would not then proceed to act just like the king" (ibid, p. 817). In the case of the English parliament subsequent to the Glorious Revolution of 1688 some answers are:

1) That "Parliament represented wealth holders" (ibid, p. 804).

2) That the relative cost of rent-seeking under Parliament is larger than under absolute monarchy (Ekelund and Tollinson 1981, p. 149).

3) The difficulty of enforcing the laws protecting rent-seekers (Tullock 1992).

All these factors can be seen in our model: The number of rent-seekers in the provisional parliament in Proposition 6. The role of $\epsilon$, the effectiveness of efforts in rent-seeking in Proposition 4. The role of $e$, the productivity in the production of rent-seeking in Proposition 3. In addition, our model points out two new factors:

1) The degree of monopoly in the product market, which depends on $\theta$-the degree of product differentiation, $\alpha$-curvature of demand, and $\gamma$ - the degree of collusion. The larger the degree of monopoly, given that returns are equalized in the rent-seeking and the productive sector-the larger the number of entrepreneurs and the less likely is that the parliament is dominated by rent-seekers.

2) The form of the demand function. The case of $\alpha>0$ is favorable to rentseekers in Remark 1 (in this case technical progress is favorable to rent-seekers) and Propositions 3 and 6 (in this case a parliament dominated by rent-seekers exists with independence of the number of active agents).

From the point of view of the theory of the firm, our main finding is that we can model corporate governance without any role for mechanism design and explain executive compensations as the surplus obtained in production and rent-seeking. Our analysis also suggests that divisionalization may foster rentseeking. This has been pointed out in a different context by Scharfstein and Stein (2000).

We end the paper by suggesting some avenues of research.

1: We have assumed that the degree of collusion is independent of the number of agents. However, the literature on supergames suggests that both variables are related (Shapiro 1989). It would be interesting to have a model were collusion is endogenous. The same applies to the degree of divisionalization.

2: In a dynamic context, it is not clear how the absolute king can sustain his standard of living if, in each period, he has to cede part of his property. This suggest that this kind of regime might not be sustainable in the long run, unless a continuous inflow of new resources are poured into the system.

14 Ekelund and Tollison suggested that the basic cause of the English Civil War (1642-1651) was the desire of the Parliament to take over the profits of the rent-seeking activities of the king. 
3: In our model rent-seekers do not perform any productive activity. However, it would be interesting to model rent-seeking as done by entrepreneurs to obtain favorable laws restricting competition and/or obtaining subsidies, etc.

4: About 300 years ago, most organizations - i.e. firms, families, universities, countries - were run by single owners. Many of these organizations in our days use voting to some degree. It would be interesting to investigate whether the prominence of voting in all these organizations has a common explanation.

\section{References}

Acemoglu D (1995) Reward structures and the allocation of talent. Eur Econ Rev 39:17-33

Acemoglu D, Johnson S, Robinson JA (2001) The colonial origins of comparative development: an empirical investigation. Am Econ Rev 91(5):1369-1401

Bates RH, Greif A, Levy M, Rosenthal J-L, Weingast BR (1998) Analytic narratives Princeton University Press

Baland J-M, Francoise P (2000) Rent-seeking and resource booms. J Develop Econ 61:527-542

Berle A, Means G (1932) The modern corporation and private property. Harcourt \& Brace

Buchanan J, Tullock G (1962) The calculus of consent: logical foundations of constitutional democracy. University of Michigan Press

Ekelund RB, Tollinson RB (1981) Mercantilism as a rent-seeking society. College Station

Easterly W, Levine R (2003) Tropic, germs and crops: how endowments influence economic development. J Monet Econo 50:3-39

Fraile-Balbín P (1991) Industrialización y grupos de presión: La economía política de la protección en España. Alianza Editorial

Glaeser E, La Porta R, López de Silanes F, Shleifer A (2004) Do institutions cause growth? J Econ Growth 9:271-303

Gradstein M (2004) Governance and growth. J Develop Econ 73:505-518

Mohtadi H, Roe T (2003) Democracy, rent-seeking, public spending and growth. J Public Econ $87: 445-466$

Murphy KM, Shleifer A, Vishny RW (1991) The allocation of talent: implications for growth. Q J Econ 106:503-530

North DC (1981) Structure and change in economic history. Norton \& Co.

North D (1990) Institutions, institutional change and economic performance. Cambridge University Press, Cambridge

North DC, Weingast BR (1989) Constitutions and commitment: the evolution of institutions governing public choice in seventeenth-century England. J Econ History XLIX:803-832

Olson M (1982) The rise and decline of nations. Yale University Press, New Haven

Pérez-Castrillo D, Verdier T (1992) A general analysis of rent-seeking games. Public Choice 71: 351-361

Rodrik D, Subramanian A, Trebi F (2004) Institutions rule: the primacy of institutions over geography and integration in economic development. J Econ Growth 9:131-165

Scharfstein D, Stein J (2000) The dark side of internal capital markets. J Financ 60:6

Shapiro C (1989) Theories of oligopoly behavior. In: Schmalensee R, Willig RD (eds) Handbook of industrial economics, vol. 1, chap. 6. North Holland

Torvik R (2002) Natural resources, rent-seeking and welfare. J Develop Econ 67:455-470

Tullock G (1980) Efficient rent-seeking. In: Buchanan JM, Tollison RD, Tullock G (eds) Towards a theory of a rent-seeking society. Texas A\&M University Press, pp 97-112

Tullock G (1992) Why the industrial revolution occur in England? In: Tullock G (ed) Economic hierarchies, organization and the structure of production. Kluwer 